\title{
The role of photodynamic therapy on multidrug resistant breast cancer
}

\author{
Eric Chekwube Aniogo, Blassan Plackal Adimuriyil George and Heidi Abrahamse*
}

\begin{abstract}
Breast cancer heterogeneity allows cells with different phenotypes to co-exist, contributing to treatment failure and development of drug resistance. In addition, abnormal signal transduction and dysfunctional DNA repair genes are common features with breast cancer resistance. Chemo-resistance of breast cancer associated with multidrug resistance events utilizes ATP-binding cassette (ABC) efflux transporters to decrease drug intracellular concentration. Photodynamic therapy (PDT) is the treatment that involves a combination of a photosensitizer (PS), light and molecular oxygen to induce cell death. This treatment modality has been considered as a possible approach in combatting multidrug resistance phenomenon although its therapeutic potential towards chemo-resistance is still unclear. Attempts to minimize the impact of efflux transporters on drug resistance suggested concurrent use of chemotherapy agents, nanotechnology, endolysosomal release of drug by photochemical internalization and the use of structurally related compound inhibitors to block the transport function of the multidrug resistant transporters. In this review, we briefly summarize the role of membrane $A B C$ efflux transporters in therapeutic outcomes and highlight research findings related to PDT and its applications on breast cancer with multidrug resistance phenotype. With the development of an ideal PS for photodynamic cancer treatment, it is possible that light activation may be used not only to sensitize the tumour but also to enable release of PS into the cytosol and as such bypass efflux membrane proteins and inhibit escape pathways that may lead to resistance.
\end{abstract}

Keywords: Breast cancer, Multidrug resistance, $P$-glycoprotein, Photosensitizer, Photodynamic therapy

\section{Introduction}

Breast cancer is the most frequent cancer amongst women and a serious public health problem all over the world. It is a dominant cause of female morbidity and mortality [1]. Global statistics as of 2017 from the American Cancer Society (ACS), estimated 252,710 and 2470 new cases of breast cancer will be diagnosed among women and men respectively. The ACS estimates that approximately 40,610 women and 460 men are expected to die from breast cancer in the same year. Breast cancer incidence and death rates generally increase with age but vary greatly in survival rates due to availability of early detection and treatment methods among racial/ ethnic groups [2]. Current treatments for breast cancer

\footnotetext{
*Correspondence: habrahamse@uj.ac.za

Laser Research Centre, Faculty of Health Sciences, University

of Johannesburg, P.O. Box 17011, Doornfontein, Johannesburg 2028,
} South Africa include; surgery, chemotherapy, immunotherapy and radiation therapy [3]. The eradication and therapeutic success of breast cancer are related to tumour stratification and dissemination patterns classified into four stages based on size, age, node involvement and tumour grade. These stages are 1; consists of well-defined and localized tumour mass, characterized by poor invasion properties. Stage 2 and 3, corresponds to an increased tumour volume and acquisition of invasive phenotype. The metastasis dissemination and a huge tumour size with invasive phenotype are classified as stage 4 [4]. Chemotherapy, radiation and targeted therapies have made major advances in patient management over the past decades but refractory diseases and recurrence remain common [5]. This is partly due to drug resistant chemotherapy caused by over expression of efflux transporters that pumps out and decreased intracellular drug accumulation [6]. Similarly, compensatory signalling also influence the molecular mode of resistance where cancer 
cells uses alternative pathways to escape treatment and inhibits cell death [7]. Taking this in consideration, breast cancer biology and its regulation, impact of efflux transporters and the role of photodynamic therapy on cancer therapeutic outcomes as well as multidrug resistance mechanism are discussed below.

\section{Lifestyle risk factors and implications in breast cancer}

Breast cancer research in the past 25 years has established many risk factors that involve genetic and behavioural factors. However, risk increases with germline and somatic mutation in the BRCA 1 and BRCA 2 genes, among other exposure to irritant carcinogenic agent that disrupts the immune and hormonal signalling, thus leads to inflammation and cancer [1]. Further research into the changes in form and appearance of epithelial cells in the mammary gland of women with cancer have revealed more evidence about the environmental lifestyle changes that initiate tumour progression. Lifestyle changes include: excessive alcohol intake, tobacco smoking as well as exposure to chemical agents or ionizing radiation. All these factors contribute to an increase in frequency of mutations and induce uncontrolled cell proliferation and metastasis through molecular interaction with proteins involved in transcriptional regulatory mechanisms $[1,8]$.

\section{Breast cancer biology and transcriptional regulation}

Breasts are made up of connective, glandular and fatty tissues that have lobes, lobules, ducts, areola and a nipple. These organ consist of a uniform structure of epithelial cells that secrete and produce milk after childbirth. Whenever there is a morphologic or functional alterations within its uniform epithelial structures, tumour initiation develops and later form a mass of multiple population of cells capable of evading physiological cell death [9].

The changes in gene expression patterns seen in breast cancer have provided evidence of epigenetic, genetic or post-translational altered expression of certain proteins, like transcription factors, co-regulators, and histone enzymes that order DNA into structural units according to recent study [10-12]. These proteins play a crucial role in the expression of genes that results in susceptibility of a healthy cell transformation malignant cell [10-12]. Among the first altered transcriptional regulation found in breast cancer were the overexpression and gene amplification of oestrogen receptor alpha $(E R \alpha)$ and avian myelocytomatosis viral oncogene homologue factor (c-myc). These two oncoproteins were found to be associated with abnormal cell division and replication within the breast $[13,14]$. Different array activity reports of transcription factors in breast cancer have also shown the involvement of Twist, Snail and Slug master factors in the final epithelial-mesenchymal transition and metastatic phenotypic characteristics [15].

Additional studies have identified inherited/acquired altered gene expression as a detectable cause of carcinogenesis of breast tissue [16]. This arise after a study of some essential genes involved in cellular processes and maintenance were found to be mutated at germ cell level [17]. Next generation sequencing analysis also found higher penetrance mutations in breast cancer 1 (BRCA1), tumour protein $\mathrm{p} 53$, mitogen-activated protein kinase 1 (MAP3K1), retinoblastoma 1 (RB1), phosphatidylinositol-4,5-bisphosphate 3-kinase catalytic subunit alpha (PIK3CA) and GATA binding protein 3 (GATA-3) genes that results in breast cancer formation $[18,19]$.

\section{Breast cancer biomarkers and drug resistance}

Several breast cancer biomarkers have been identified of which the estrogen receptor (ER), progesterone receptor (PR) and human epidermal growth factor receptor 2 (HER2) constitute the main markers. These markers represent therapeutic targets and may also play important roles in diagnosis and prediction of prognosis [20]. Their expression closely correlates with differences in tumor behavior and therapeutic responses for example, positive expression of either ER or PR is termed hormone receptor positive $(\mathrm{HR}+)$ breast cancer. This tumor type will likely respond and receive endocrine therapy, while HER2+ breast cancers will receive HER2 targeted therapies. A negative expression of these biomarkers is called triple-negative breast cancer (TNBC) which comprises $15-20 \%$ of all breast cancers $[21,22]$. TNBC is the most serious type of tumor and its molecular classification is characterized by a negative profile of ER, PR, and HER2 [23]. According to Shaheen et al. [22], these receptors helps in targeted therapy and effective treatment of breast tumors. Histopathologic features of this tumor include a high nuclear mitotic activity with a high nuclearcytoplasmic ratio that accelerate its proliferation and make its' metastases highly difficult to recognize, hence referred to as metastases with unknown origin [23]. Research have found multi-drug resistance associated genes and their products, abnormal cell signal transduction, DNA repair abnormality genes as well as cell cycle checkpoint kinase 2 (CHEK2) gene dysfunction as factors closely associated with TNBC drug resistance [24]. Pro-inflammatory cytokines derived from either dying cells or tumor micro-environment may play a role in the development of TNBC resistance to therapy. Xu et al. [25] reported that TGF- $\beta$ contributes to TNBC development of drug resistance through apoptotic, stemness and epithelial-to-mesenchymal transition regulation [25]. The 
standard of care for TNBC is neoadjuvant chemotherapy which can increase the chances of developing drug resistance. Studies by Kim [26] and his colleagues conducted at single-cell genomic DNA and RNA sequencing level revealed that TNBC harbored many residual tumor cells with clonal differences. Their data suggests that TNBC have pre-existing resistant clonal cells or adaptively selected resistant cells acquired by reprogramming in response to chemotherapy [26].

\section{The multidrug cancer resistance}

Resistance often follows initial response to chemotherapy and has remained a problem to cancer therapy. Multidrug resistance (MDR) is a phenomenon that involve a multitude of factors highlighted in Fig. 1, where certain tumour cells has the ability to evade the cytotoxic effects of a broad range of structurally and functionally unrelated drug.

This phenomenon can be intrinsic; when cancer cells show innate ability to resist drug treatment at initial exposure or, acquired; when cancer cells gain resistance through the active efflux of drugs during chemotherapy $[9,27]$.

Various mechanisms attributed to MDR includes; (1) Increased expression of drug efflux transporters; where the proteins of ATP-binding cassette family acts to protect cells by ejecting a wide variety of anticancer drug, rendering the cell resistant. (2) Changes in tumour microenvironment and cancer stem cell regulation; tumour microenvironment that comprises of stromal cells, extracellular matrix, cytokines and growth factors, all contribute to direct cell interaction mediated by drug resistance. (3) Elevating adaptability by epigenetic and microRNA regulation; hyper-methylation of oncogenes and demethylation of drug resistance genes leads to acquisition of resistance [28]. (4) Altered drug target; associated with rapid down-regulation or mutation of drug targets lead to drug structure modification in the protein, improper binding and eventually drug resistance. (5) Reduced susceptibility to apoptosis and

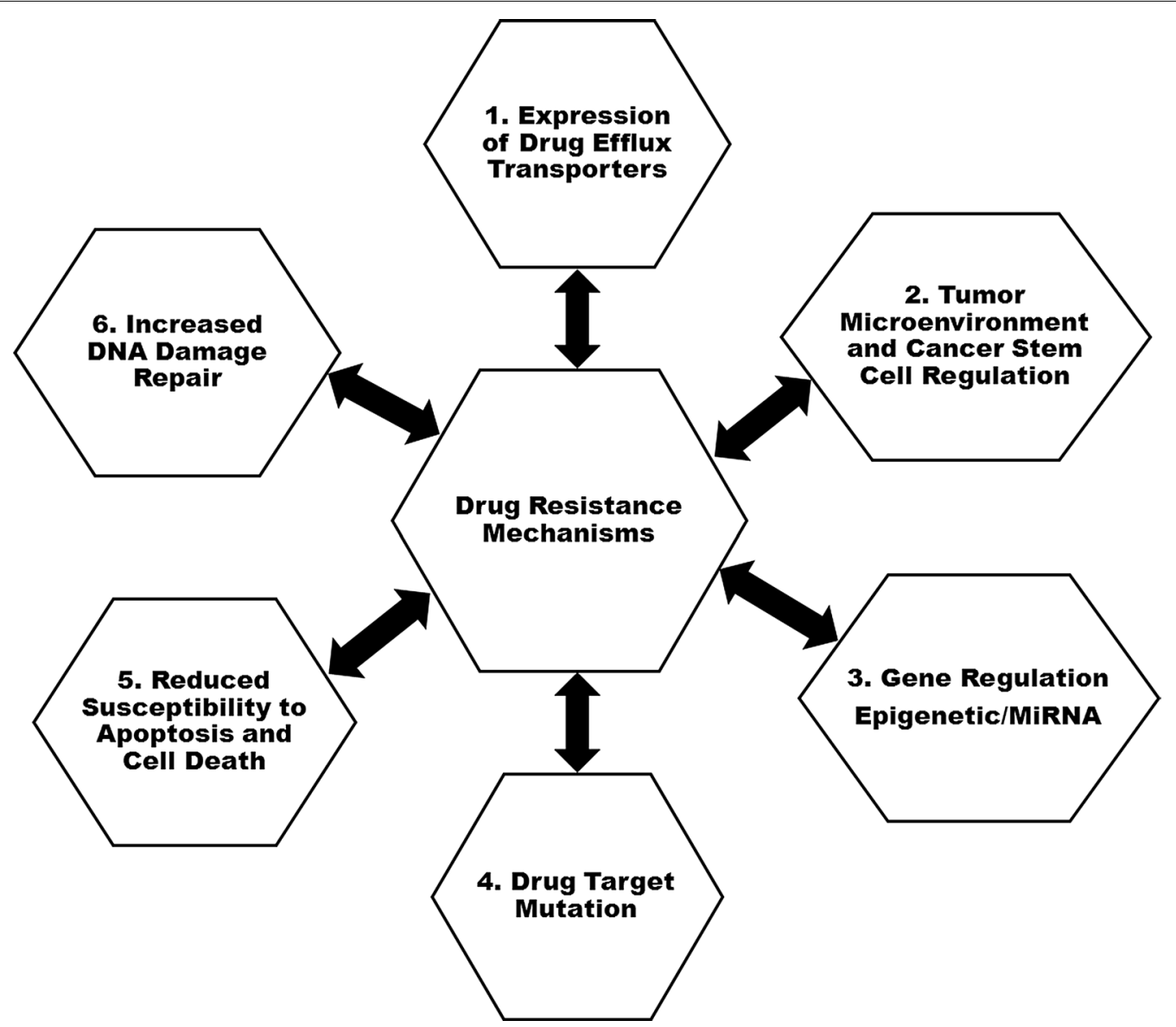

Fig. 1 Hallmark of multidrug cancer resistance mechanisms. Tumour cells developed resistance through; increased expression of drug efflux transporters, microenvironment tumour regulation, increased epigenetic microRNA regulations, drug target modification, altered apoptotic signalling pathway and increased DNA repair mechanism 
cell death; avoidance of apoptosis through increased expression level of $\mathrm{B}$ cell lymphoma (BCL) family proteins that block apoptotic signalling pathways is among the important resistance mechanism of cancer cells. (6) Increased DNA damage repair system; damaged DNA or replication errors are continuously detected and fixed by DNA proofreading and repair mechanisms (Fig. 1) [29]. Further classifications are based on cellular mechanisms which are grouped into classical transporter and non-transporter-based MDR phenotypes. Different $A B C$ transporters identified in a human genome have been classified into seven subgroups $(A-G)$ based on sequence similarities and structural organization [30]. This classification grouped four members of classes (A, $\mathrm{B}, \mathrm{C}$ and G) as classic transporters capable of conferring drug resistance [31]. The classic transporters including $p$-glycoprotein ( $P$-gp, gene symbol ABCB1), breast cancer resistance proteins (BCRP, gene symbol ABCG2) and multidrug resistance-associated proteins (MRP, gene symbol $\mathrm{ABCC} 1$ ) enables the cells to efflux anticancer drug thus, decreasing the intracellular concentration of the drug [32, 33]. The process called efflux-transport mechanism is mainly associated with the overexpression of the ATP-binding cassette proteins which protects the cell in physiological conditions, by forming a unique defence network against cellular toxicants $[9,34]$. It is generally believed that $\mathrm{ABC}$ transporters possess multiple drug binding sites in a large pocket formed by transmembrane $\alpha$-helices that facilitates transportation across membrane in a competitive-dependent manner [35].

\section{Multidrug resistance mediated by efflux transporters}

Multidrug resistance mediated by drug efflux ATP-binding cassette $(A B C)$ transporters emerged in the 1970s as an important phenomenon to explain/account for the clinical resistance of cells to standard chemotherapy. With the identification of other drug efflux pumps, it's now clear that chemo sensitivity and resistance are governed by these transporters as well as other genetic and environmental factors [9, 36, 37]. Importantly, rapid up regulation of efflux transporters was reported to contribute in decreased intracellular anticancer drug accumulation thereby precluding the therapeutic efficacy and consequently MDR. The main features and structure of $P$-gp, MRP and BCRP with respect to cancer and their cellular localization are illustrated in Fig. 2.

\section{P-glycoproteins (P-gp/ABCB1)}

One of the three well-characterized transporters associated with chemo-resistant mechanisms of a variety of drugs is $P$-glycoprotein. It's a transmembrane glycoprotein molecule with the size of $170-\mathrm{kDa}$ that acts as an energy-dependent efflux transporter [38]. It consists of 1280 amino acids constituted by two transmembrane domains (TMDs), each consisting of six transmembrane segments and two nucleotide binding domains linked with $\mathrm{N}$ - and C-termini (Fig. 2) [9, 39, 40]. P-glycoprotein, an energy-dependent export transporter was the first human ABC transporter identified in 1976 [41]. This protein is known to transport and efflux a different variety of hydrophobic compounds including cancer drugs [31, 42]. P-gp is prominently expressed in the epithelial cells of mouse and human tissues at the physiological barriers such as the blood-brain barrier, gastrointestinal tract, kidney and liver [43]. Its location at the apical membrane of endothelial cells enable its protective effect. The overexpression of this protein, associated with MDR has led to the identification of many important drugs that can serve as substrate that bind and enhance its transport function [44]. P-gp have a high flexible drug binding sites that enable its interaction with hundreds of structurally diverse chemical compounds, including anticancer drugs, steroid hormones and hydrophobic toxic peptides [45]. Another important feature of $P$-gp is that it recognizes and transports hydrophobic drugs or substrates thus suggesting lipid membrane partitioning as an essential step for its transport [39]. Despite understanding of the structure and cellular localization of $P$-gp, its precise molecular mechanism of drug transport is still not fully understood. Nevertheless, several hypothetical models like hydrophobic vacuum cleaner and lipid flippase activity have tried to explain the mechanism of substrate efflux by $P$-gp. According to the vacuum cleaner model of $P$-gp function, the drug/substrate are partitioned into the membrane and are spontaneously translocated into the cytoplasmic leaflet where it gains access to the $P$-gp substrate binding sites from within the bilayer interior and subsequently effluxes into the extracellular environment. In the lipid flippase activity model, drugs/substrates are flipped to the outer membrane leaflet after gaining access to the $P$-gp substrate binding sites. Both activity models cause dimerization of the two nucleotide binding domains and thus ATP hydrolysis which returns the protein back to its inward facing drug binding conformation and reinitiates the transport cycle $[39,46]$. In tumour cells that express $P$-gp, this would result in reduced intracellular concentrations, which decreases the cytotoxicity of several anticancer agents. However, there are possibilities that there might be other complementary mechanisms that are directly related to anticancer drug efflux which can confer resistance. Studies have demonstrated correlation between elevated $P$-gp expression and patient response rate following chemotherapy. Trock and colleagues [47] examined $P$-gp expression in patients with breast cancer after administration of chemotherapy 


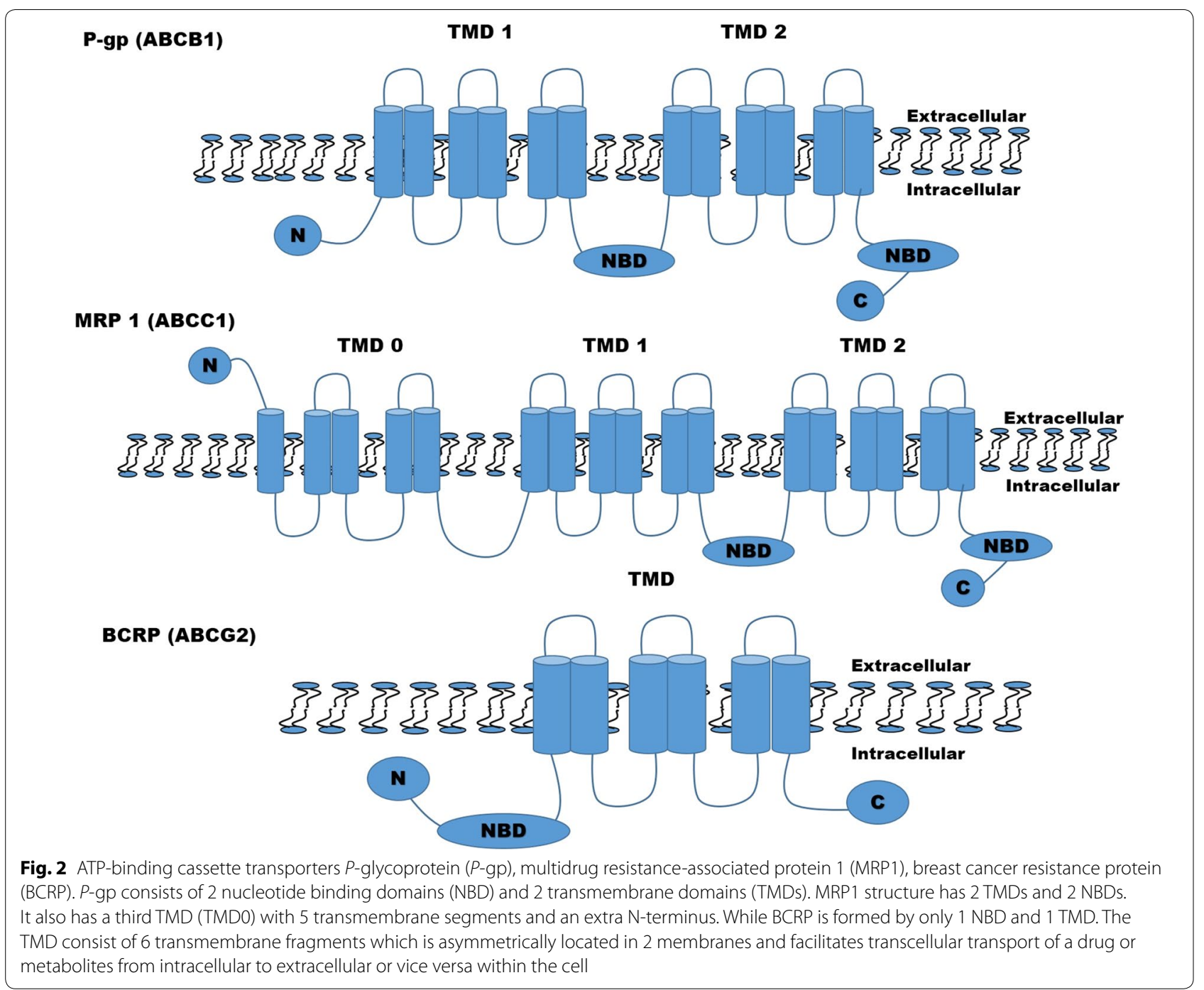

and the study showed a threefold likelihood of patients with over expression of $P$-gp not to respond to chemotherapy than other patients. Other studies by Triller et al. [48] and Leith et al. [49] contradicted the report of Trock and his team by demonstrating that there is no relationship between patient's response to therapy and $P$-gp expression.

\section{Multidrug resistance-associated protein (MRP)}

Phylogenetic analysis of human genome have identified and characterized 45 human $\mathrm{ABC}$ genes, which have been grouped into seven subfamilies: A-G. The subfamily $\mathrm{C}$ group comprises of nine proteins often referred to as MRPs (multidrug resistance proteins) or ABCC proteins [50]. This transporter protein utilizes the power of ATP binding and hydrolysis to move their physiological and pharmacological substrates across the plasma membrane [51]. There are two types of MRPs; the short
(MRP4, MRP5, MRP8 and ABCC12) and long (MRP1, MRP2, MRP3, ABCC6 and MRP7). Both types contain the $\mathrm{ABC}$ structure with two nucleotide and three transmembrane domains (Fig. 2). The TMDs contain the transmembrane helices that form the translocation pathway through which substrates are transported across the membrane. These transport proteins have different substantial transport kinetics with a degree of overlapping substrate specificity. MRP's transport a large number of molecules derived from exogenous and endogenous sources across the plasma membrane except for the proteins encoded by the ABCC6 and $\mathrm{ABCC} 12$ genes that are not known to transport drugs; hence they are not referred to as MRP6 and MRP12. Each MRPs have their unique pharmacological and physiological functions as well as differences in tissue distribution and membrane localization. Some in vitro studies have established that MRP1 is responsible for resistance to many widely used 
anticancer drugs; hence it is considered the most clinical relevant MRPs [52]. This $190-\mathrm{kDa}$ transmembrane protein is mainly found and distributed in all organs conferring resistance of cell to several structurally unrelated cytotoxic agents across blood-organ interfaces [53]. Later after MRP1 was discovered to confer multidrug resistance, Leier and co-workers [52] also discovered that MRP1 have a high affinity for pro-inflammatory cytokine leukotriene (LTC4). The study by Wijnholds et al. [54], confirmed the key physiologic role of MRP1 in mediating LTC4 export. Their study together with Ishikawa [55] demonstrated that MRP1 was (at least one of) the ubiquitous ATP-dependent GSH conjugate pumps that facilitates the transport of substance across membrane. Additionally, reports from Slot et al. [51] have also demonstrated the role of MRP2 and MRP4 in the elimination process of xenobiotics and their metabolites from the bile and urinary system. Equally, if not important, these xenobiotic-transporting proteins have contributed to the pharmacokinetics profiles, efficacy and toxicity of a large number of therapeutic and diagnostic agents found in the environment and diet [51].

\section{Breast cancer resistance protein (BCRP)}

Breast cancer resistance protein is a polytopic transmembrane (TM) protein with 655 amino acids. It's the second member of the subfamily $G$ of the large human ATP-binding cassette $(A B C)$ superfamily with gene symbol ABCG2 according to HUGO nomenclature [35]. Whereas in $\mathrm{CD}$ (clusters of differentiation) nomenclature, it was assigned the term CD338 by the Human Cell Differentiation Molecules Organization [36]. Unique distinguishing features of BCRP from other efflux transporters like $p$-gp and MRP1 are on its structure which only have one nucleotide-binding domain that precedes one membrane spanning domain (Fig. 2). These domain organizations are opposite to that of $P$-gp and MRP1 which accounts for differences in its transport mechanism [56]. The BCRP can function as homo or heterodimer with molecular mass ranging from 72 to $180 \mathrm{kDa}$ [57]. Biological research of $\mathrm{ABC}$ family proteins revealed that $\mathrm{BCRP}$ is normally expressed in the gut, bile canaliculi, blood brain barriers, placenta and the renal proximal tubular cells where they function as a defence mechanism to protect tissue against xenobiotic exposure as well as contribute to the absorption, distribution, and elimination of drugs and endogenous compounds [35]. The role of BCRP in drug disposition has become an area of interest because of its high resemblance with $P$-gp in tissue, and also because of its distribution and expression with similar substrate and inhibitor specificity (Table 1) [35]. Over the past two decades, BCRP protein have been under intense study to demonstrated its role in drug resistance to anthracycline anticancer drugs on MCF-7 cell line in the absence of overexpression of known multidrug resistance transporters such as P-gp or MRP1 [58]. Doyle and his team reported a direct involvement of BCRP in natural resistance and longevity of normal stem cells. Their report leads to the assessment of any relationship between BCRP expression and clinical outcomes in breast cancer and other solid tumours. Burger and his co-workers [59] found a positive correlation between BCRP mRNA expression and response to patients receiving anthracycline-based chemotherapy in breast cancer. Alternative study also examined BCRP expression and its resistance to 5-fluorouracil (a BCRP substrate) in 140 breast cancer tissue specimens, and found that resistance to 5-fluorouracil was significantly correlated with the levels of BCRP expression [60]. Further correlation between high levels of BCRP expression and poor clinical outcomes particularly in acute myeloid leukaemia have also been reported [36]. Even though the role of BCRP in drug resistance in cancer has not been well established, its role as an active efflux transporter on drug absorption, distribution, metabolism and excretion has been understood [36]. A variety of PS including pheophorbide

Table 1 Selected substrates and inhibitors of $P$-gp/ABCB1, MRP/ABCC1, and BCRP/ABCG2 as chemosensitizers

\begin{tabular}{|c|c|c|c|}
\hline $\begin{array}{l}\text { Efflux protein } \\
\text { transporters }\end{array}$ & Substrate & Inhibitors & References \\
\hline$P-g p / A B C B 1$ & $\begin{array}{l}\text { 5-Fluorouracil, doxorubicin, paclitaxel, vincristine, } \\
\text { vinblastine, vindesine, vinorelbine, mitoxantrone, } \\
\text { topotecan, actinomycin D }\end{array}$ & $\begin{array}{l}\text { Cyclosporin A, quinine, verapamil, valspodar, tariquidar, } \\
\text { zosuquidar, laniquidar, dexverapamil, nifedipine, quini- } \\
\text { dine, chlorpromazine }\end{array}$ & $\begin{array}{l}{[39,45,93,96} \\
\quad 97]\end{array}$ \\
\hline $\mathrm{MRP} / \mathrm{ABCC} 1$ & $\begin{array}{l}\text { Daunorubicin, imatinib, doxorubicin, melphalan, } \\
\text { chlorambucil, saquinivir, vincristine, irinotecan, } \\
\text { ciprofloxacin, mitoxantrone }\end{array}$ & $\begin{array}{l}\text { Biricodar/NX-710, cyclosporine A, efavirenz elacridar/ } \\
\text { GG918/GF120918, verapamil, agosterol A, curcumin, } \\
\text { disulfiram, flavonoids, clotrimazole, steroid analogues, } \\
\text { probenecid }\end{array}$ & {$[53,96,98-100]$} \\
\hline BCRP/ABCG2 & $\begin{array}{l}\text { Mitoxantrone, camptothecin derivatives, methotrex- } \\
\text { ate, lamivudine, prazosin, cimetidine, nilotinib, } \\
\text { nitrofurantoin, flavopiridol, gefitinib }\end{array}$ & $\begin{array}{l}\text { Cyclosporine A, sirolimus, tamoxifen, omeprazole, } \\
\text { piperine, novobiocin, dofequidar, nelfinavir, boceprevir, } \\
\text { fluconazole, dipyridamole }\end{array}$ & {$[35,96]$} \\
\hline
\end{tabular}


A, protoporphyrin IX, and related compounds have been identified as BCRP substrates [61]. However, several studies now are looking towards overcoming cancer drug resistance using $\mathrm{BCRP}$ inhibitors.

\section{Breast cancer stem cell in therapeutic resistance and relapse}

Accumulating evidence now suggest that human cancers including breast, lungs, cervical, leukaemia, among others are driven by a subset of cells with the capability of self-renewal ability to generate and differentiate into a functional mature progeny. These cells are known as cancer stem cells and were first isolated from acute myeloid leukaemia by John Dick and colleagues [62]. The cellular hierarchy and organization within the breast are structured in a way that stem cells generate all progeny and terminally differentiated cells with specialized functions of milk production. In breast cancer, a subpopulation of cells that displayed stem cell properties was identified and characterized by cell surface markers CD44 expression and are thus called "breast cancer stem cells" (BCSCs) [62]. Subsequent to identification of BCSCs in primary mouse xenografts model, a small population of the cells have shown to be more invasive than the differentiated cells which comprise the tumour bulk. More evidence now suggest that these cells contribute to cancer relapse following treatments [63]. The relative resistance associated with BCSCs appears to be multifactorial ranging from decreased level of oxidants production and increased DNA repair efficiency that help maintain their stemness. Moreover, the preferential targeting of rapidly dividing cells by most chemotherapy enables the BCSCs in their quiescent non-cycling state to persist after therapy $[64,65]$. Another molecular mechanism mediating breast cancer resistance to trastuzumab chemotherapy is inactivation of the tumour suppressor PTEN, which activate the downstream Akt molecule and bypass HER2 activation [62].

\section{Unique mechanism of photodynamic therapy}

Photodynamic therapy is an approved treatment regime for several cancer types that involves systemic use of a non-toxic light sensitive compound (PS) and a subsequent light excitation of the PS by an appropriate wavelength to induce cancer death [66]. This treatment modality requires three components; PS, light and molecular oxygen to exert a cytotoxic effect. The PS absorbs energy from light in the form of photon and undergo energy transfer to either tissue substrate (Type I reaction) or molecular oxygen (Type II reaction) which results in the production of superoxide anion radicals and reactive singlet oxygen molecules respectively (Fig. 3) [67, 68].
The consequence of excess ROS production will cause vital tissue peroxidation and initiation of cell death mechanisms $[69,70]$. The photo-damaging effect of PDT greatly depends on factors like type of PS used, dose administered, light exposure, light fluency, oxygen availability, sensitizer localization, drug administration time interval and many more [71]. It has been observed that following PDT, there are blood vessel occlusion, collapse and ultimate vascular shutdown due to excessive radical formation and hypoxia. This causes apoptosis and necrosis [72]. Moreover, PDT can also mediate destruction of tumour-infected cells through immune modulation. The radical formation results in cell signal transduction that activate apoptotic proteins and cytokine gene expression [73].

Although PDT is a site-directed therapy, its efficacy that depends on excess ROS production that can directly kill tumour cells and/or cause inflammatory immune response with tumour vasculature shutdown [74]. A major challenge in PDT technology is to acquire the therapeutic relevant PS level and retention in the target tissue. This is because of the presence of overexpressed multidrug resistance proteins among tumour cells which pumps out PS and prevents its localization. This upregulation of multidrug resistance protein especially $P$-gp have been described as the most important resistance mechanisms. The cytoprotective functions of some intracellular antioxidants like the glutathione system, catalase, lipoamide de-hydrogenase, and superoxide dismutase which detoxify PDT-induced ROS, result in treatment resistance [69]. A major cause of cancer development is the escape of T-cell recognition thus, PDT have shown to induce T-cell mediated anti-tumour immunity [75]. Reports have shown PDT to be specific treatment modalities with fewer side effects. More several research effort and strengths have been focused to demonstrate the advantages of PDT in overcoming MDR.

\section{The role of photodynamic therapy in overcoming multidrug cancer resistance}

Emerging evidence now suggests that the damage and unique mechanism of photodynamic treatment on tumour and its microenvironment could possibly inhibit drug resistance pathways and re-sensitize resistant cells to standard therapies. Photoactive compound used in PDT localize at cellular organelle such as the mitochondria, lysosome, endoplasmic reticulum and possibly Golgi apparatus within the cytoplasm [76]. Upon photodamage, these intracellular membranes including their protein components are destroyed thus leading to cell death via any of the normal modes-necrosis, autophagy or apoptosis. The photo-damage of PDT via lysosome 


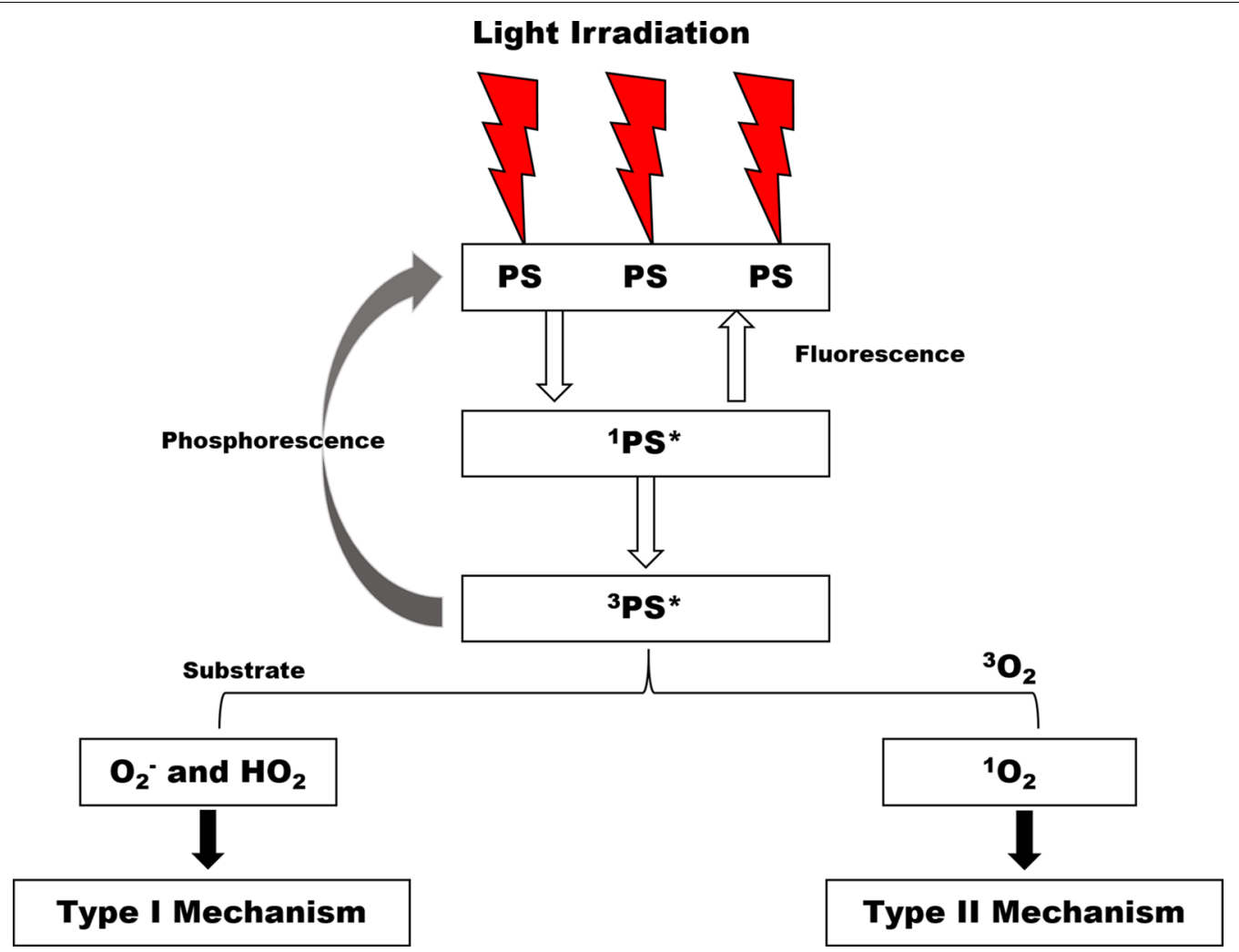

Fig. 3 The photosensitization process of PDT. When PS absorbs photon energy, it transits from ground singlet state (PS) to an excited singlet state ( $\left.{ }^{1} P S^{*}\right)$ which then undergoes internal conversion and changes to a triplet state ( $\left.{ }^{3} P S^{*}\right)$. The triplet PS reacts with either tissue substrate (Type I mechanism) to form a superoxide anion radicals or with molecular oxygen to form a reactive oxygen species (Type II mechanism)

(Lyso-PDT) and mitochondria (mito-PDT) are the most common and well-studied. PS that localized in the lysosome leads to spillage of proteases upon irradiation which activates the proapoptotic factor BID (tBID) that enhance cell death. Whereas mito-PDT damage antiapoptotic proteins of the BCL-2 family. This causes BAX translocation to the outer mitochondria membrane and stimulates the release of cytochrome $\mathrm{c}$ that drives the cells alone the irreversible path to apoptosis (Fig. 4) [7].

This mechanism of apoptotic induction bypasses many regulatory checkpoints that accounts for resistance and triggers increased susceptibility of tumour cells to death rather than MDR development. Some investigations have shown that photo-destruction of breast cancer resistant protein rich extracellular vesicles could facilitate photoactive drugs towards reaching its target without been entrapped or sequestrated outside the cell [34]. This approach results in direct damage to proteins involved in drug resistance and shut down tumour microvasculature, thus stimulates drug delivery and antitumor immunity [34, 77]. The time interval between PS administration and photo-irradiation which is very unique to PDT can be utilized and exploited depending on the pharmacokinetics of the PS to shut down tumour microvasculature [7].

Photochemical internalization (PCI) is another novel technological approach used to facilitate the cytosolic delivery of macromolecular drugs. This drug and gene therapy delivery method is developed to release macromolecules into the cytosol and by so doing, bypass the efflux pumps proteins that transport xenobiotics out of the cancer cells. The PCI treatment is based on same principles of PDT except in its aim which is to induce cancer cell death by the macromolecular drug delivered and not primarily by photochemical reaction [78]. PCI has been demonstrated to facilitate the intracellular release of anticancer agents or PS that are targeted for intracellular organelles. Emerging evidence support the therapeutic potential of PCI to circumvent mechanisms associated with resistance towards chemotherapeutics [78]. Furthermore, none of the PCI components including a macromolecular drug, amphiphilic PS and light are subjected to cellular efflux which enables PCI a treatment strategy for cancer stem-like cells [79].

Additionally, several researchers have reported in vitro experimental evidence of PDT potentiation in 
overcoming MDR and re-sensitizing the susceptibility of tumour cells to treatment. One of such studies includes early investigations by Kusuzaki and colleagues [80] that studied the effect of PDT using acridine orange on mouse osteosarcoma cells with MDR phenotype and observed a strong cytotoxic effect [80]. Similarly, Kulbacka et al. [81] used the FDA approved Photofrin PS on MDR adenocarcinoma cells and observed a comparable oxidative alterations in both sensitive and resistant cells. Also, MDR Jurkat/A4 leukaemia cells showed reduced sensitivity and no cross-resistance to ALA-mediated PDT [82]. Another study using same ALA PS with different cell line, MCF-7 MDR phenotype also showed a less effective treatment in comparison with MCF-7 parental cells [83]. Feuerstein and co-workers tested the effect of a novel ALA-derived prodrug on MCF-7 resistant sublines and the result showed a higher potent effect on the viability of the resistant cells even without laser irradiation. This indicate that ALA-derived prodrug based PDT has the effectiveness of treating resistant cancer malignancies [84]. Another most recent report by Chen et al. [85] indicated that PDT mediated by meso-5-[ $p$-diethylene triaminepenta acetic acid-aminophenyl]-10,15,20-triphenyl-porphyrin (DTP) have a significant effect on Adriamycin-resistant breast cancer cells to an extent of recovering its sensitivity to Adriamycin. Chen and colleagues [85] also suggested that DTP-PDT could exhibit inhibition of MDR1 gene expression at molecular level with an important realistic significance. More also, Kukcinaviciute et al. [86] demonstrated the usefulness of mTHPC-mediated PDT on 5-fluorouracil resistant human colorectal cancer cells. These studies highlights the role of PDT in chemo-resistance reversal and potentiation in MDR.

In recent years, application of Nano-carriers and targeting technology to overcome MDR has been recognized as an important and promising field of research. Current research are now beginning to focus on the use of nanotechnology to deliver PS to specific target cells/ tissues in an attempt to mitigate problems associated with poor selectivity and tumour targeting of the PS. This involve the use of drug delivery system loaded with PS to bypass the efflux transporters and enhance intracellular accumulation [87]. The use of Nano-carriers, such as polymeric nanoparticles, and magnetic nanoparticles can facilitate delivery of PS without been entrapped by efflux transporters [88]. A novel nanoceria-mediated drug delivery nanocomposites, synthesized by Hong and colleagues was used to load PS for targeted PDT. They reported that the nanocomposites carrying the PS selectively accumulated in lysosome triggered production of reactive oxygen species and reduced $P$-gp expression. This approach promotes the effectiveness of PDT in the treatment of drug-resistant human breast cancer cells [88]. Drug delivery system combined with targeting technology holds great potential and may provide the possibilities of targeting at gene level, the proteins responsible for MDR $[45,78,89]$.

\section{Modulation of multidrug resistance}

Novel strategies to modulate MDR in cancer cells including targeting $\mathrm{ABC}$ transporters using substrates and inhibitors are currently underway to eliminate and suppress drug resistance [45]. At molecular level, microRNA and RNA interference including synthetic siRNAs are extensively been used to reverse multidrug resistance by inhibiting the expression of genes associated with MDR. For instance, Bao and colleagues were able to modulate multidrug resistance in human breast cancer using miR298. Their study observed that overexpression of miR-298 down-regulated $P$-gp expression, and increases nuclear accumulation of doxorubicin and cytotoxicity in resistant breast cancer cells [38].

Another more achievable approach is the use of antiMDR strategies which include MDR inhibitors or substrates [45]. MDR transporters especially $P$-gp have proven to interact with various structurally unrelated compounds classified as substrates and modulators. This substrate actively binds to and is transported in and out of the cell while modulators bind and block the transport function of the MDR transporter. The anti-MDR strategy of using an inhibitor to alter the function of the transporter proteins have shown significant clinical applications in cancer chemotherapy [90]. There are three different generations of inhibitors developed for MDR transporter up till date; first generation inhibitors including verapamil and cyclosporine A were found to reverse drug resistance profile in leukemic and lungs cancer cells respectively $[91,92]$.

Its low therapeutic response and unacceptable toxicity drive the development of the second generation of inhibitors such as dexverapamil, valspodar and biricodar citrate which showed a better tolerability but displayed unwanted pharmacokinetic interaction with cytochrome P450 [45, 93]. Continuous problems with MDR necessitates the development of a specific and more potent three generation MDR transporter inhibitor that can reverse MDR with almost no pharmacokinetic interaction with other chemotherapeutic drugs. This inhibitors include; tariquidar (XR9576), zosuquidar (LY335979), laniquidar (R101933) and elacridar (F12091) [45, 93, 94]. Recent studies have noted that tariquidar can also act as a substrate depending on its in vivo dosage to $P$-gp [95]. Another achievable approach to circumvent drug resistance besides the use of $\mathrm{ABC}$ transporter inhibition, is by 


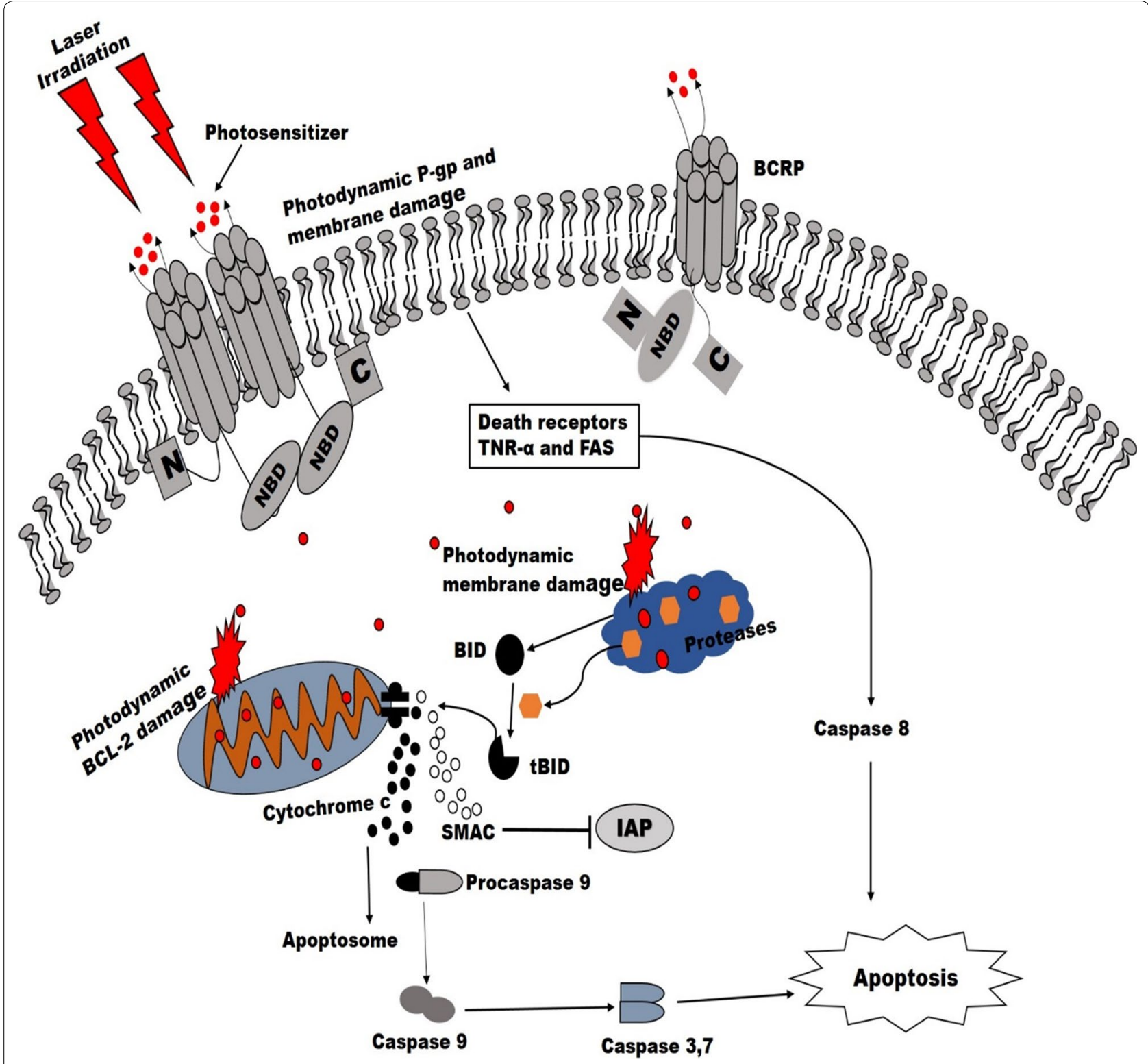

Fig. 4 Overview of unique mechanisms of PDT-induced apoptosis on multidrug resistant cells. Light activation directly damages drug efflux pumps ( $P$-gp and BCRP) involved in classical drug resistance and release PS into the cytosol which localizes on mitochondria and lysosome. Upon activation, damages the antiapoptotic BCL-2 family proteins and lysosomal membrane. The Lyso-PDT induces the proteolytic activity that cleaves BID to tBID and leads to mitochondria pore opening via BAX action. The pore opening caused the release of cytochrome $c$ and SMAC (second mitochondrion-derived activator of caspases) from the intermembrane mitochondrion space. The SMAC promotes caspase activation by binding with IAPs (inhibitor of apoptosis protein) and cytochrome c forms complex which leads to cell death through caspase action. Membrane damage after PDT leads to depolarization, reduction of active transport and lipid peroxidation which help in activation of death signal and thus cell death

substituting drugs that are not subject to efflux transport system. Kathawala and his colleagues [44] in their report postulated that $\mathrm{ABC}$ transporter inhibitor known as chemosensitizers may be used in combination with standard chemotherapy to enhance therapeutic efficacy.

\section{Conclusion and future perspectives}

Developing therapeutic strategies for breast cancer, especially the type characterized by lack of ER, PR, and HER2 expression, have been a challenge since 
these receptors are involved in targeted therapy. TNBC exhibit a higher risk for drug resistance and cancer relapse. In recent years, the therapeutic effects of PDT in cancer treatment are encouraging especially in palliative end point. This remains an area of interest with the possibility of serving as an alternative to broad spectrum antibiotic-based therapy and thus limits the development of drug resistance. The treatment modality of PDT is still questioned by some scientists mostly its efficacy in huge and metastases widespread tumour. The targeted delivery of PS to diseased cells is still a challenge in PDT. Since PS that accumulates in malignant tissue are crucial to photo-medicine, it is essential that more research should focus on the development of a suitable PS composed of either antibody or nanoparticles to enhance efficiency and reduce the chances of drug efflux pumps. This will further compensate the lack of specificity and selectivity potential of a raw PS. Recent advancements have shown combination treatment strategies comprising PDT and other concurrent treatments to have a better response in cancer recurrence. The improved response was due to molecular response, boosted antitumor immunity and susceptibility of cancer cells following PDT which leads to improve overall treatment outcome. Immunotherapy using drug delivery system could also be used to bypass the efflux transporters and deliver PS into tumour cells thus maximize treatment efficacy and thwart survival mechanism in resistant tumour. In addition to this development, PDT resistant cells should also be used as a model to further study the impact of PDT on the cellular targets. Moreover, PDT studies on MDR tumour cells with focus on the multidrug resistant phenotype on PS uptake might shed light and contribute to the circumvention of drug resistance. It is expected that this review will hopefully stimulate innovative preclinical and clinical PDT research against multidrug resistance cancer cells.

\footnotetext{
Abbreviations

ABC: ATP-binding cassette; $A B C B 1$ : P-glycoprotein gene symbol; $A B C C 1$ : multidrug resistance protein gene symbol; $A B C G 2$ : breast cancer resistance protein gene symbol; ACS: American Cancer Society; AKT: protein kinase B; ALA: aminolevulinic acid; ATP: adenosine triphosphate; BAX: $\mathrm{BCl}-2$ associated X protein; BCL: B cell lymphoma; BCRP: breast cancer resistance protein; BCSCs: breast cancer stem cells; BID: $\mathrm{BH} 3$ interacting domain death agonist; BRCA1: breast cancer 1; BRCA2: breast cancer 2; CD: cluster of differentiation; CHEK2: cell cycle checkpoint kinase 2; C-Myc: avian myelocytomatosis; DNA: deoxyribonucleic acid; DTP: meso-5-[p-diethylene triaminepenta acetic acid-aminophenyl]-10,15,20-triphenyl-porphyria; ER: oestrogen receptor; ERa: oestrogen receptor alpha; FDA: Food and Drug Administration; GATA-3: GATA binding protein 3; GSH: glutathione; HER2: human epidermal growth factor receptor 2; HR+: hormone receptor positive; HUGO: Human Genome Organisation; IAPs: inhibitor of apoptosis protein; kDa: kilodalton; LTC4: leukotriene cytokine; MAP3K1: mitogen-associated protein kinase 1; MCF-7: breast cancer cell line; MDR: multidrug resistance; MRP: multidrug resistance-associated
}

protein; mTHPC: meta-tetra(hydroxyphenyl)chlorin; NBDs: nucleotide binding domains; PCl: photochemical internalization; PDT: photodynamic therapy; P-gp: P-glycoprotein; PIK3CA: phosphatidylinositol-4,5-bisphosphate 3-kinase catalytic subunit alpha; PR: progesterone receptor; PS: photosensitizer; PTEN: phosphatase and tensin homolog; P53: tumour suppressor protein; RB1: retinoblastoma 1; RNA: ribonucleic acid; ROS: reactive oxygen species; SMAC: second mitochondrion-derived activator of caspases; TGF- $\beta$ : transforming growth factor beta; TM: transmembrane; TMDs: transmembrane domains; TNBC: triple negative breast cancer.

\section{Authors' contributions}

ECA prepared the manuscript. BPAG conceptualized the idea for the research and was involved in revising the manuscript for its intellectual content, and is a postgraduate co-supervisor of the lead author. HA provided professional guidance for the project and supplied editorial input and is the supervisor of the lead author. All authors read and approved the final manuscript.

\section{Authors' information}

Eric Chekwube Aniogo is a doctoral student in the Laser Research Centre, in the Faculty of Health Sciences at the University of Johannesburg, South Africa. He is currently investigating the phototoxic effect of a photosensitizer on a multidrug resistant human breast cancer cell line.

Blassan P. George received his doctoral degree in Biotechnology from Bharathiar University, Coimbatore, Tamil Nadu, India. He is a researcher in the Laser Research Centre, Faculty of Health Sciences, at the University of Johannesburg, South Africa. His research interest lie in the area of phytochemistry, pharmacology, molecular biology and photodynamic therapy where he investigates the anticancer and photodamage effect of medicinal plant extracts. He serves as a reviewer of more than 8 international peer reviewed journals.

Heidi Abrahamse Ph.D. Wits, (Biochemistry, Molecular Biology), is currently the Director of the Laser Research Centre, University of Johannesburg and Department of Science and Technology/National Research Foundation SARCHI Chair for Laser Applications in Health. Her research interests includes, photobiology and photochemistry with specific reference to photodynamic cancer therapy, stem cell differentiation and wound healing. She serves on the editorial boards of 8 peer-reviewed internationally accredited journals while acting as reviewer for over 50 journals. She is also a co-Editor in Chief of the international accredited journal Photomedicine and Laser Surgery.

\section{Acknowledgements}

The authors sincerely thank the African Laser Centre (ALC) for postgraduate student monetary support. This work is based on the research supported by the South African Research Chairs Initiative of the Department of Science and Technology and National Research Foundation of South Africa (Grant No. 98337), as well as grants received from the University of Johannesburg (URC), the National Research Foundation (NRF), and the CSIR (Council for Scientific and industrial Research)—NLC (National Laser Centre) Laser Rental Pool Programme.

The material in this research paper submitted to Cancer Cell International has neither been published, nor is being considered elsewhere for publication.

\section{Competing interests}

The authors declare that they have no competing interests.

\section{Availability of data and materials}

No datasets were generated or analysed.

\section{Consent of publication}

All authors have reviewed the manuscript and agree to publish it in its current form.

\section{Ethics approval and consent to participate}

Not applicable.

\section{Funding}

The authors disclosed receipt of the following financial support for the research, authorship, and/or publication of this article: this work is based on the research supported by the South African Research Chairs Initiative of the 
Department of Science and Technology and National Research Foundation of South Africa (Grant No. 98337).

\section{Publisher's Note}

Springer Nature remains neutral with regard to jurisdictional claims in published maps and institutional affiliations.

Received: 2 November 2018 Accepted: 5 April 2019

Published online: 11 April 2019

\section{References}

1. Patel S. Breast cancer: lesser-known facets and hypotheses. Biomed Pharmacother. 2018;98:499-506.

2. American Cancer Society. Breast cancer facts and figures 2017-2018. p. $1-41$.

3. Tobias J, Hochhanser D. Breast cancer in cancer and its management. 7th ed. New York: Wiley; 2015. p. 237-74.

4. Cadoo KA, Fornier MN, Morris PG. Biological subtypes of breast cancer: current concepts and implications for recurrence patterns. Q J Nucl Med Mol Imaging. 2013;57(4):312-21.

5. Barrera-Rodriguez R, Fuentes JM. Multidrug resistance characterization in multicellular tumour spheroids from two human lung cancer cell lines. Cancer Cell Int. 2015;15:47

6. Chen Z, Shi T, Zhang L, Zhu P, Deng M, Huang C, Hu T, Jiang L, Li J. Mammalian drug efflux transporters of the ATP binding cassette (ABC) family in multidrug resistance: a review of the past decade. Cancer Lett. 2016;370:153-64

7. Spring BQ, Rizvi I, Xu N, Hasan T. The role of photodynamic therapy in overcoming cancer drug resistance. Photochem Photobiol Sci. 2015;14(8):1476-91

8. Anand P, Kunnumakara AB, Sundaram C, Harikumar KB, Tharakan ST, Lai SO, Sung B, Aggarwal BB. Cancer is a preventable disease that requires major lifestyle changes. Pharm Res. 2008;25(9):2097-116.

9. Videira M, Reis RL, Brito MA. Deconstructing breast cancer cell biology and the mechanisms of multidrug resistance. Biochim Biophys Acta. 2014;1846:312-25.

10. Cipollini G, Tommasi S, Paradiso A, Aretini P, Bonatti F, Brunetti I, Bruno M, Lombardi G, Schittulli F, Sensi E, et al. Genetic alterations in hereditary breast cancer. Ann Oncol. 2004;15(1):17-13.

11. Hnisz D, Abraham BJ, Lee TI, Lau A, Saint-Andre V, Sigova AA, Hoke HA, Young RA. Super-enhancers in the control of cell identity and disease. Cell. 2013;155(4):934-47.

12. Whyte WA, Orlando DA, Hnisz D, Abraham BJ, Lin CY, Kagey $\mathrm{MH}$, Rahl PB, Lee TI, Young RA. Master transcription factors and mediator establish super-enhancers at key cell identity genes. Cell. 2013;153(2):307-19.

13. Tripathy D, Benz CC. Activated oncogenes and putative tumour suppressor genes involved in human breast cancers. In: Liu ET, Benz CC, editors. Oncogenes and tumor suppressor genes in human malignancies. Cancer treatment and research. Boston: Springer; 1993. p. 15-60.

14. Hopp TA, Fuqua SA. Estrogen receptor variants. J Mammary Gland Biol Neoplasia. 1998;3(1):73-83.

15. Yang J, Mani SA, Donaher JL, Ramaswamy S, Itzykson RA, Come C, Savagner P, Gitelman I, Richardson A, Weinberg RA. Twist, a master regulator of morphogenesis, plays an essential role in tumor metastasis. Cell. 2004:117(7):927-39.

16. Pérez-Solis MA, Maya-Nuñez G, Casas-González P, Olivares A, AguilarRojas A. Effects of the lifestyle habits in breast cancer transcriptional regulation. Cancer Cell Int. 2016. https://doi.org/10.1186/s1293 5-016-0284-7

17. Watson IR, Takahashi K, Futreal PA, Chin L. Emerging patterns of somatic mutations in cancer. Nat Rev Genet. 2013;14(10):703-18.

18. Cancer Genome Atlas N. Comprehensive molecular portraits of human breast tumours. Nature. 2012;490(7418):61-70.

19. Pop L, Cojocneanu-Petric R, Pileczki V, Morar-Bolba G, Irimie A, Laza V, Lombardo C, Paradiso A, Berindan-Neagoe I. Genetic alterations in sporadic triple negative breast cancer. Breast. 2018;38:30-8.
20. Lal S, Mc Cart Reed AE, de Luca XM, Simpson PT. Molecular signatures in breast cancer. Methods. 2017;131:135-46.

21. Hudis CA, Gianni L. Triple-negative breast cancer: an unmet medical need. Oncologist. 2011;16(1):1-11.

22. Shaheen S, Fawaz F, Shah S, Busselberg D. Differential expression and pathway analysis in drug-resistant triple negative breast cancer cell lines using RNASeq analysis. Int J Mol Sci. 2018;19(6):1810.

23. Jitariu A, Cimpean AM, Ribatti D, Raica M. Triple negative breast cancer: the kiss of death. Oncotarget. 2017;8:46652-62.

24. Luo L, Gao W, Wang J, Wang D, Peng X, Jia Z, Jiang Y, Li G, Tang D, Wang Y. Study on the mechanism of cell cycle checkpoint kinase 2 (CHEK2) gene dysfunction in chemotherapeutic drug resistance of triple negative breast cancer cells. Med Sci Monit. 2018;15(24):3176-83.

25. Xu X, Zhang L, He X, Zhang P, Sun C, Xu X, Lu Y, Li F. TGF- $\beta$ plays a vital role in triple-negative breast cancer (TNBC) drug-resistance through regulating stemness, EMT and apoptosis. Biochem Biophys Res Commun. 2018;502(1):160-5.

26. Kim C, Gao R, Sei E, Brandt R, Hartman J, Hatschek T, Crosetto N, Foukakis T, Navin NE. Chemoresistance evolution in triple-negative breast cancer delineated by single-cell sequencing. Cell. 2018;173(4):879-93.

27. Pokharel D, Padula MP, Lu JF, Tacchi JL, Luk F, Djordjevic SP, Bebawy M. Proteome analysis of multidrug-resistant, breast cancer-derived microparticles. J Extracell Vesicles. 2014. https://doi.org/10.3402/jev.v3.24384.

28. Mansoori B, Mohammadi A, Davudian S, Shirjang S, Baradaran B. The different mechanisms of cancer drug resistance: a brief review. Adv Pharm Bull. 2017;7(3):339-48.

29. Cree IA, Charlton P. Molecular chess? Hallmarks of anticancer drug resistance. BMC Cancer. 2017;17(10):1-8.

30. Dean M, Rzhetsky A, Allikmets R. The human ATP-binding cassette (ABC) transporter superfamily. Genome Res. 2001;11(7):1156-66.

31. Ambudkar SV, Kimchi-Sarfaty C, Sauna ZE, Gottesman MM. P-glycoprotein: from genomics to mechanism. Oncogene. 2003;22(47):7468-85.

32. Huang $Z$, Hsu Y, Li L, Wang L, Song $X$, Yow CMN, Lei $X$, Musani A, Luo R, Day BJ. Photodynamic therapy of cancer-challenges of multidrug resistance. J Innov Opt Health Sci. 2015:8(1):1-13.

33. Biochuk S, Galembikova A, Sitenkov A, Khusnutdinov R, Dunaev $P$, Valeeva E, Usolova N. Establishment and characterization of a triple negative basal-like breast cancer cell line with multidrug resistance. Oncol Lett. 2017;14:5039-45.

34. Goler-Baron $V$, Assaraf YG. Overcoming multidrug resistance via photodestruction of ABCG2-rich extracellular vesicles sequestering photosensitive chemotherapeutics. PLoS ONE. 2012;7(4):e35487. https ://doi.org/10.1371/journal.pone.0035487.

35. Mao Q, Unadkat JD. Role of the breast cancer resistance protein (BCRP/ ABCG2) in drug transport-an update. AAPS J. 2015;17(1):65-82.

36. Natarajan $K$, Xie $Y$, Baer MR, Ross D. Role of breast cancer resistance protein (BCRP/ABCG2) in cancer drug resistance. Biochem Pharm. 2012;83:1084-103.

37. Xia CQ, Smith PG. Drug efflux transporters and multidrug resistance in acute leukemia: therapeutic impact and novel approaches to mediation. Mol Pharmacol. 2012;82(6):1008-21.

38. Bao L, Hazari S, Mehra S, Kaushal D, Moroz K, Dash S. Increased expression of $P$-glycoprotein and doxorubicin chemoresistance of metastatic breast cancer is regulated by miR-298. Am J Pathol. 2012;180(6):2490-503.

39. Binkhathlan Z, Lavasanifar A. P-glycoprotein inhibition as a therapeutic approach for overcoming multidrug resistance in cancer: current status and future perspectives. Curr Cancer Drug Targets. 2013;13:326-46.

40. Hu T, Li Z, Gao C, Cho C. Mechanism of drug resistance in colon cancer and its therapeutic strategies. World J Gastroenterol. 2016;22(30):6876-89.

41. Juliano RL, Ling V. A surface glycoprotein modulating drug permeability in Chinese hamster ovary cell mutants. Biochim Biophys Acta. 1976:455(1):152-62

42. Szakacs G, Paterson JK, Ludwig JA, Booth-Genthe C, Gottesman MM. Targeting multidrug resistance in cancer. Nat Rev Drug Discov. 2006;5(3):219-34

43. Fletcher J, Williams RT, Henderson MJ, Norris MD, Haber M. ABC transporters as mediators of drug resistance and contributors to cancer cell biology. Drug Resist Update. 2016;26:1-9. 
44. Kathawala RJ, Gupta P, Ashby CR, Chen ZS. The modulation of ABC transporter-mediated multidrug resistance in cancer: a review of the past decade. Drug Resist Update. 2015;18:1-17.

45. Li W, Zhang H, Assaraf YG, Zhao K, Xu X, Xie J, Yang D, Chen Z. Overcoming $A B C$ transporter-mediated multidrug resistance: molecular mechanisms and novel therapeutic drug strategies. Drug Resist Update. 2016;27:14-29.

46. Sharom FJ. Complex interplay between the $P$-glycoprotein multidrug efflux pump and the membrane: its role in modulating protein function. Front Oncol. 2014. https://doi.org/10.3389/fonc.2014.00041.

47. Trock BJ, Leonessa F, Clarke R. Multidrug resistance in breast cancer: a meta-analysis of MDR1/gp170 expression and its possible functional significance. J Natl Cancer Inst. 1997;89(13):917-31.

48. Triller N, Korosec P, Kern I, Kosnik M, Debeljak A. Multidrug resistance in small cell lung cancer: expression of $P$-glycoprotein, multidrug resistance protein 1 and lung resistance protein in chemo-naïve patients and in relapsed disease. Lung Cancer. 2006;54(2):235-40.

49. Leith CP, Kopecky KJ, Chen IM, Eijdems L, Slovak ML, McConnell TS, Head DR, Weick J, Grever MR, Appelbaum FR, et al. Frequency and clinical significance of the expression of the multidrug resistance proteins MDR1/P-glycoprotein, MRP1, and LRP in acute myeloid leukemia: a southwest oncology group study. Blood. 1999;94(3):1086-99.

50. Dean M, Allikmets R. Complete characterization of the human ABC gene family. J Bioenerg Biomembr. 2001;33(6):475-9.

51. Slot AJ, Molinski SV, Cole SP. Mammalian multidrug resistance proteins (MRPs). Essays Biochem. 2011;50(1):179-207.

52. Leier I, Jedlitschky G, Buchholz U, Cole SP, Deeley RG, Keppler D. The MRP gene encodes an ATP-dependent export pump for leukotriene C4 and structurally related conjugates. J Biol Chem. 1994;269(45):27807-10.

53. Barnouin K, Leier I, Jedlitschky G, Pourtier-Manzanedo A, Konig J, Lehmann WD, Keppler D. Multidrug resistance protein-mediated transport of chlorambucil and melphalan conjugated to glutathione. $\mathrm{Br}$ J Cancer. 1998;77(2):201-9.

54. Wijnholds J, Evers R, van Leusden MR, Mol CA, Zaman GJ, Mayer U, Beijnen $\mathrm{JH}$, van der Valk M, Krimpenfort P, Borst P, Borst P. Increased sensitivity to anticancer drugs and decreased inflammatory response in mice lacking the multidrug resistance-associated protein. Nat Med. 1997;3(11):1275-9.

55. Ishikawa T. The ATP-dependent glutathione S-conjugate export pump. Trends Biochem Sci. 1992;17(11):463-8

56. Ni Z, Bikadi Z, Rosenberg MF, Mao Q. Structure and function of the human breast cancer resistance protein (BCRP/ABCG2). Curr Drug Metab. 2010;11(7):603-17.

57. Litman T, Jensen U, Hansen A, Covitz KM, Zhan Z, Fetsch P, Abati A, Hansen PR, Horn T, Skovsgaard T, et al. Use of peptide antibodies to probe for the mitoxantrone resistance-associated protein MXR/BCRP/ ABCP/ABCG2. Biochem Biophys Acta. 2002;1565(1):6-16.

58. Doyle LA, Yang W, Abruzzo LV, Krogmann T, Gao Y, Rishi A, Ross DD. A multidrug resistance transporter from human MCF-7 breast cancer cells. Proc Natl Acad Sci. 1998:95(26):15665-70.

59. Burger H, Foekens JA, Look MP, Meijer-van H, Gelder ME, Klijn JG, Wiemer EA, Stoter G, Nooter K. RNA expression of breast cancer resistance protein, lung resistance-related protein, multidrug resistanceassociated protein 1 and 2, and multidrug resistance gene 1 in breast cancer: correlation with chemotherapeutic response. Clin Cancer Res. 2003;9(2):827-36

60. Yuan JH, Cheng JQ, Jiang LY, Ji WD, Guo LF, Liu JJ, Xu XY, He JS, Wang $X M$, Zhuang ZX. Breast cancer resistance protein expression and 5-fluorouracil resistance. Biomed Environ Sci. 2008;21(4):290-5.

61. Robey RW, Steadman K, Polgar O, Bates SE. ABCG2-mediated transport of photosensitizers: potential impact on photodynamic therapy. Cancer Biol Ther. 2005;4:187-94.

62. Korkaya H, Malik F. Breast cancer stem cells: responsible for therapeutic resistance and relapse? In: Ahmad A, editor. Breast cancer metastasis and drug resistance. New York: Springer; 2013. p. 385-98.

63. Huiwen $Y$, Pengcheng B. Non-coding RNAs in cancer stem cells. Cancer Lett. 2018;421:121-6.

64. Rich JN. Cancer stem cells in radiation resistance. Cancer Res. 2007;67(19):8980-4.
65. Diehn M, Cho RW, Lobo NA, Kalisky T, Dorie MJ, Kulp AN, Qian D, Lam JS, Allies LE, Wong M, et al. Association of reactive oxygen species levels and radioresistance in cancer stem cells. Nature. 2009;456(7239):780-3.

66. Kwiatkowski S, Knap B, Przystupski D, Saczko J, Kedzierska E, KnapCzop K, Kotlinska J, Michel O, Kotowski K, Kulbacka J. Photodynamic therapy-mechanisms, photosensitizers and combinations. Biomed Pharmacother. 2018;106:1098-107.

67. Baptista MS, Cadet J, Di-Mascio P, Ghogare AA, Greer A, Hamblin MR, Lorente C, Nunez SC, Ribeiro MS, Thomas AH, et al. Type I and type II photosensitized oxidation reactions: guidelines and mechanistic pathways. Photochem Photobiol. 2017;93(4):912-9.

68. Banerjee SM, MacRobert AJ, Mosse CA, Periera B, Bown SG, Keshtgar MRS. Photodynamic therapy: inception to application in breast cancer. Breast. 2017;31:105-13.

69. Olsen CE, Weyergang A, Edwards VT, Berg K, Brech A, Weisheit S, Hogset A, Selbo PK. Development of resistance to photodynamic therapy (PDT) in human breast cancer cells is photosensitizer-dependent: possible mechanisms and approaches for overcoming PDT-resistance. Biochem Pharmacol. 2017;144:63-77.

70. Verma S, Watt GM, Mai Z, Hasan T. Strategies for enhanced photodynamic therapy effects. Photochem Photobiol. 2007:83(5):996-1005.

71. Abrahamse $\mathrm{H}$, Hamblin RM. New photosensitizers for photodynamic therapy. Biochem J. 2016;473:347-464.

72. Oniszczuk A, Wojtunik-Kulesza KA, Oniszczuk T, Kasprzak K. The potential of photodynamic therapy (PDT) - experimental investigations and clinical use. Biomed Pharmacother. 2016:83:912-29.

73. Wachowska M, Muchowicz A, Demkow U. Immunological aspects of antitumor photodynamic therapy outcome. Cent Eur J Immunol. 2015;40(4):481-5.

74. Postiglione I, Chiaviello A, Palumbo G. Enhancing photodynamic therapy efficacy by combination therapy: dated, current and oncoming strategies. Cancers. 2011;3(2):2597-629.

75. Anzengruber F, Avci P, de-Freitas LF, Hamblin MR. T-cell mediated antitumor immunity after photodynamic therapy: why does it not always work and how can we improve it? Photochem Photobiol Sci. 2015;14(8):1492-509.

76. Chen J, Mao L, Liu S, Liang Y, Wang S, Wang Y, Zhao Q, Zhang X, Che $Y, G a o L$, et al. Effects of a novel porphyrin-based photosensitizer on sensitive and multidrug-resistant human gastric cancer cell lines. J Photochem Photobiol B. 2015;151:186-93.

77. Castano AP, Mroz P, Wu MX, Hamblin MR. Photodynamic therapy plus low-dose cyclophosphamide generates antitumor immunity in a mouse model. Proce Natl Acad Sci. 2008;105(14):5495-500.

78. Weyergang A, Berstad ME, Bull-Hansen B, Olsen CE, Selbo PK, Berg K. Photochemical activation of drugs for the treatment of therapyresistant cancers. Photochem Photobiol Sci. 2015;14(8):1465-75.

79. Bostad M, Kausberg M, Weyergang A, Olsen CE, Berg K, Hogset A, Selbo PK. Light-triggered, efficient cytosolic release of IM7-saporin targeting the putative cancer stem cell marker CD44 by photochemical internalization. Mol Pharm. 2014;11(8):2764-76.

80. Kusuzaki K, Minami G, Takeshita H, Murata H, Hashiguchi S, Nozaki T, Ashihara T, Hirasawa Y. Photodynamic inactivation with acridine orange on a multidrug-resistant mouse osteosarcoma cell line. Jpn J Cancer Res. 2000;91:439-45.

81. Kulbacka J, Chwilkowska A, Bar J, Pola A, Banas T, Gamian A, Saczko J. Oxidative alterations induced in vitro by the photodynamic reaction in doxorubicin-sensitive (LoVo) and resistant (LoVoDX) colon adenocarcinoma cells. Exp Biol Med. 2010;235(1):98-110.

82. Philchenkov AA, Schishko ED, Zavelevich MP, Kuiava LM, Miura K, Blokhin DY, Shton IO, Gamaleia NF. Photodynamic responsiveness of human leukemia Jurkat/A4 cells with multidrug resistant phenotype. Exp Oncol. 2014;36(4):241-5.

83. Tsai T, Hong R, Tsai JC, Lou PJ, Ling IF, Chen CT. Effect of 5-aminolevulinic acid-mediated photodynamic therapy on MCF-7 and MCF-7/ ADR cells. Lasers Surg Med. 2004;34(1):62-72.

84. Feuerstein T, Berkovitch-Luria G, Nudelman A, Rephaeli A, Malik Z. Modulating ALA-PDT efficacy of multidrug resistant MCF-7 breast cancer cells using ALA prodrug. Photochem Photobiol Sci. 2011;10(12):1926-33. 
85. Chen J, Liu S, Zhao J, Wang S, Liu T, Li X. Effects of a novel photoactivated photosensitizer on MDR1 over-expressing human breast cancer cells. J Photochem Photobiol B. 2017;171:67-74.

86. Kukcinaviciute E, Sasnauskiene A, Dabkeviciene D, Kirveliene V, Jonusiene $\mathrm{V}$. Effect of mTHPC-mediated photodynamic therapy on 5-fluorouracil resistant human colorectal cancer cells. Photochem Photobiol Sci. 2017;16(7):1063-70.

87. Yuan Y, Cai T, Xia X, Zhang R, Chiba P, Cai Y. Nanoparticle delivery of anticancer drugs overcomes multidrug resistance in breast cancer. $J$ Drug Deliv. 2016;9:3350-7.

88. Hong L, Liu C, Zeng Y, Hao Y, Huang J, Yang Z, Li R. Nanoceriamediated drug delivery for targeted photodynamic therapy on drugresistant breast cancer. ACS Appl Mater Interfaces. 2016:8:31510-23.

89. Liang XJ, Chen C, Zhao Y, Wang PC. Circumventing tumor resistance to chemotherapy by nanotechnology. Methods Mol Biol. 2010;596:467-88

90. Shukla S, Chen ZS, Ambudkar SV. Tyrosine kinase inhibitors as modulators of $A B C$ transporter-mediated drug resistance. Drug Resist Update. 2012;15(1-2):70-80.

91. Tsuruo T, lida H, Tsukagoshi S, Sakurai Y. Overcoming of vincristine resistance in P388 leukemia in vivo and in vitro through enhanced cytotoxicity of vincristine and vinblastine by verapamil. Cancer Res. 1981;41(5):1967-72.

92. Twentyman PR, Fox NE, White DJ. Cyclosporin A and its analogues as modifiers of Adriamycin and vincristine resistance in a multi-drug resistance human lung cancer cell line. Br J Cancer. 1987;56(1):55-7.

93. Xu Y, Zhi F, Xu G, Tang X, Lu S, Wu J, Hu Y. Overcoming multidrugresistance in vitro and in vivo using the novel $P$-glycoprotein inhibitor 1416. Biosci Rep. 2012;32(6):559-66.
94. Kelly RJ, Draper D, Chen CC, Robey RW, Figg WD, Piekarz RL, Chen X, Gardner ER, Balis FM, Venkatesan AM, et al. A pharmacodynamics study of the docetaxel in combination with the $P$-glycoprotein antagonist tariquidar (XR9576) in patients with lung, ovarian and cervical cancer. Clin Cancer Res. 2011;17(3):569-80.

95. Kannan P, Telu S, Shukla S, Ambudkar SV, Pike VW, Halldin C, Gottesman MM, Innis RB, Hall MD. The "specific" P-glycoprotein inhibitor Tariquidar is also a substrate and an inhibitor for breast cancer resistance protein (BCRP/ABCG2). ACS Chem Neurosci. 2011;2(2):82-9.

96. Ween MP, Armstrong MA, Oehler MK, Ricciardelli C. The role of ABC transporters in ovarian cancer progression and chemoresistance. Crit Rev Oncol Hematol. 2015;96:220-56.

97. Zhang Y, Yang S, Guo X. New insights into Vinca alkaloids resistance mechanism and circumvention in lung cancer. Biomed Pharmacother. 2017;96:659-66.

98. Priebe W, Krawczyk M, Kuo MT, Yamane Y, Savaraj N, Ishikawa T. Doxorubicin and daunorubicin-glutathione conjugates, but not unconjugated drugs, competitively inhibit leukotriene C4 transport mediated by MRP/GS-X pump. Biochem Biophys Res Commun. 1998;247(3):859-63.

99. Deeley RG, Cole SP. Substrate recognition and transport by multidrug resistance protein 1 (ABCCI). FEBS Lett. 2006;580(4):1103-11.

100. Liu Y, Di Y, Zhou Z, Mo S, Zhou S. Multidrug resistance-associated proteins and implications in drug development. Clin Exp Pharmacol Physiol. 2010;37:115-20.
Ready to submit your research? Choose BMC and benefit from:

- fast, convenient online submission

- thorough peer review by experienced researchers in your field

- rapid publication on acceptance

- support for research data, including large and complex data types

- gold Open Access which fosters wider collaboration and increased citations

- maximum visibility for your research: over $100 \mathrm{M}$ website views per year

At BMC, research is always in progress.

Learn more biomedcentral.com/submissions 